\title{
Erratum to: Bicarbonate therapy in the treatment of septic shock: a second look
}

\author{
Ali A. El-Solh • Philippe Abou Jaoude • \\ Jahan Porhomayon
}

Published online: 10 March 2010

(c) SIMI 2010

\section{Erratum to: Intern Emerg Med}

DOI 10.1007/s11739-010-0351-3

Unfortunately, the article was published under the wrong section. The section should be EM - ORIGINAL.

The online version of the original article can be found under doi:10.1007/s11739-010-0351-3.

A. A. El-Solh ( $\square)$

The Veterans Affairs Western New York Healthcare System, Medical Research Blg 20 (151) VISN02, 3495 Bailey Avenue, Buffalo, NY 14215-1199, USA

e-mail: solh@buffalo.edu

\section{A. A. El-Solh · P. Abou Jaoude}

Division of Pulmonary, Critical Care, and Sleep Medicine, Department of Medicine, Western New York Respiratory, Research Center, Buffalo, NY, USA
A. A. El-Solh
Department of Social and Preventive Medicine, State University of New York at Buffalo School of Medicine and Biomedical Sciences and School of Public Health and Health Professions, Buffalo, NY, USA
J. Porhomayon
Department of Anesthesia, State University of New York at Buffalo School of Medicine and Biomedical Sciences and School of Public Health and Health Professions, Buffalo, NY, USA 